\title{
SYNTHESIS AND CHARACTERIZATION OF POLY([(2-methacryloyloxy) ethyl]) TRIMETHYLAMONNIUM CHLORIDE) RESIN WITH REMOVAL PROPERTIES FOR VANADIUM(V) AND MOLYBDENUM(VI)
}

\author{
D. V. MORALES, B. L. RIVAS*, M. GONZÁLEZ \\ Polymer Department, Faculty of Chemistry, University of Concepción, Casilla 160-C, Concepción, Chile.
}

\begin{abstract}
It was successful synthesized the ion exchange resin poly([(2-methacryloyloxy) ethyl]) trimethylammonium chloride) PCIMETA by radical polymerization to study the removal properties towards vanadium (V) and molybdenum (VI) and compared with the commercial resin AmberliteIRA-402 which contains the same functional group. The resin was characterized by FT-IR and SEM. Parameters including water adsorption capacity, effect of the $\mathrm{pH}$, maximum retention capacity of the metal ions, elution, regeneration, adsorption time, and adsorption isotherms were studied. All the studies were carried out in Batch and Column equilibrium procedures. Thermodynamic parameters such as enthalpy, entropy, and free energy were calculated. The PCIMETA resin showed higher capacity to remove V(V) and $\mathrm{Mo}(\mathrm{VI})$ from water solution than Amberlite IRA-402 commercial resin. The higher capacity displayed by PClMETA resin was attributed to the higher degree of swelling and different structure that Amberlite IRA-402 resin.
\end{abstract}

\section{INTRODUCTION}

With the rapid development of industries such as metal plating facilities, mining operations, fertilizer, tanneries, batteries, paper, and pesticides, etc., heavy metals wastewaters are directly or indirectly discharged into the environment increasingly, especially in developing countries. Unlike organic contaminants, heavy metals are not biodegradable and tend to accumulate in living organisms and many heavy metal ions are known to be toxic or carcinogenic [1].

Heavy metal pollution has become one of the most serious environmental problems today. The treatment of heavy metals is of special concern due to their recalcitrance and persistence in the environment. In recent years, various methods for heavy metal removal from wastewater have been extensively studied [2-9]. These technologies include chemical precipitation, ion exchange, adsorption, membrane filtration, coagulation-flocculation, flotation and electrochemical methods. It is evident from the literature survey articles that ion exchange, adsorption, and membrane filtration are the most frequently studied for the treatment of heavy metal wastewater.

Among the metal ion as oxyanions, molybdenum and vanadium occur in the earth crust in a mean concentration of about $0.0001 \%$ and $150 \mathrm{~g} / \mathrm{t}$, respectively [10].

Therefore, vanadium is one of the most commonly found metals. Since the 1980s a new type of secondary raw materials has gained importance for the production of these metals, namely the molybdenum-containing catalysts, widely used in the petroleum refining industry.

Due to fact that environmental legislation is becoming strict, emission and deposition of these residues must be drastically reduced. Several methods dealing with the extraction of molybdenum and vanadium from different sources are been reported. Among them are liquid extraction, ion exchange, flotation, and sorption onto chitosan [11-17]

Equilibrium in aqueous solutions of molybdenum (VI) is been studied in detail. At molybdenum concentrations greater than $10^{-3} \mathrm{~mol} \mathrm{l}^{-1}$ at $\mathrm{pH}>6$ the predominant species is the tetrahedral $\left[\mathrm{MoO}_{4}\right]^{2-}$ ion. As the $\mathrm{pH}$ is lowered polymerization condensation occurs giving at $\mathrm{pH}$ 5-6 the heptamolybdate ion $\left[\mathrm{Mo}_{7} \mathrm{O}_{24}\right]^{6-}$ and at $\mathrm{pH}$ 3-5 the octamolybdate ion $\left[\mathrm{Mo}_{8} \mathrm{O}_{26}\right]^{4-}$. Both ions are built up from linked $\mathrm{MoO}_{6}$ octahedral. At $\mathrm{pH} 0.9 \mathrm{MoO}_{3}$ precipitates and in more acidic solutions the $\left[\mathrm{MoO}_{2}\right]^{2+}$ ion is formed [18].

The chemical similarities of the various molybdate species and the fact that they are in equilibrium in aqueous media mean that major differences are unlikely in their physiological effects. [19-20]

The aim of this contribution is to evaluate the removal properties of a water-insoluble polymer, resin, containing ammonium group, for molybdenum and vanadium under experimental conditions.

\section{EXPERIMENTAL}

\section{Materials}

The reagents used to synthesize the ion exchange resins, poly[(2methacryloyloxyethyl) trimethylammonium chloride], PCIMETA resin were (2-methacryloyloxyethyl) trimethylammonium chloride 75\%, N,N'-methylene- bis-acrylamide (99\%), and ammonium persulfate (98\%). All these reagents and the Amberlite IRA-402 commercial resin were purchased from Sigma-Aldrich. The reagents to study the removal properties were ammonium metavanadate (p.a), ammonium heptamolybdate (99\%), hydrochloric acid (37\%), and nitric acid (65\%). All the salts and acid solutions were purchased from Merck.

\section{Synthesis of PCIMETA}

The PCIMETA resin was synthesized at laboratory scale by radical polymerization using (2-methacryloyloxyethyl) trimethylammonium chloride, $\mathrm{N}, \mathrm{N}^{\prime}$-methylene-bis-acrylamide ( $4 \mathrm{~mol} \%$ ), and $1 \mathrm{~mol} \%$ of ammonium persulfate was used as monomer, crosslinking reagent and initiator, respectively. All of the reagents were introduced into a polymerization flask with $10 \mathrm{~mL}$ of water and were kept under a $\mathrm{N}_{2}$ atmosphere for $24 \mathrm{~h}$ at $70^{\circ} \mathrm{C}$. The resin was filtered, washed with distilled water, and dried in an oven at $40^{\circ} \mathrm{C}$ until constant weight was obtained. Finally, the dry resin was milled sieved to give the particle size between 250 and $180 \mathrm{~mm}$. The synthetic route of PCIMETA resin is shown in Figure 1. The structure of the Amberlite IRA-402 commercial resin used for reference is shown in Figure $2^{[21]}$.

\section{Instrumentation}

The laboratory equipment used in the experimental stage of this research included: (a) a Shimadzu AUX 220 analytical balance; (b) a Wisebath thermostatic bath; (c) a Memmert heater; (d) a Perkin Elmer PinAAcle 900F atomic absorption spectrometer; (e) a digital $\mathrm{pH}$ meter Toledo seven compact; (f) a Magnetic stirrer Wisestir MSH-20 $0^{\mathrm{a}}$; (g) a scanning electron microscope, Jeol JSM-6380 LV (h) TF-IR spectrometer 550, Magna Nicolet; (i) a set of stainless steel sieves of 100, 180, and $250 \mu \mathrm{m}$; (j) a basic grinder IKA A11; (k) a fraction collector Spectra/ Chrom CF-2, and (1) a peristaltic pump Kross Flo research I.

\section{Characterization}

The PCIMETA resin was characterized by FT-IR spectroscopy over the range of 400 to $4000 \mathrm{~cm}^{-1}$ to identify the typical absorption signals of the resin exchange groups.

The PCIMETA resin also was characterized by SEM (scanning electron microscopy) to observe the morphology of the resin charged with metal ion and alone, at 100,50 , and $5 \mathrm{~mm}$.

Finally, it was also analyzed by TGA (thermogravimetric analysis) the profile of decomposition of the resin was running between $0-550^{\circ} \mathrm{C}$ under $\mathrm{N}_{2}$ atmosphere and a heating rate of $10^{\circ} \mathrm{C} / \mathrm{min}$.

\section{Degree of swelling}

The resin swelling was determined by using $100 \mathrm{mg}$ of dry resin and 80 $\mathrm{mL}$ of bidistilled water were introduced and kept in a $100-\mathrm{mL}$ beaker over $24 \mathrm{~h}$. For this study was used the particle size of the resin between 180 and $250 \mu \mathrm{m}$.

Once the residence time was completed, the beaker content was filtered and the wet resin was weighed to obtain the mass of water absorbed per gram of resin (see Eq. 1). The resins were classified as (a) xerogel $\left(0 \mathrm{~g} \mathrm{H}_{2} \mathrm{O} / \mathrm{g}\right.$ resin), (b) hydrogel (0-100 g H $\mathrm{g}_{2} \mathrm{O} / \mathrm{g}$ resin), and (c) superabsorbent (higher than $100 \mathrm{~g}$ $\mathrm{H}_{2} \mathrm{O} / \mathrm{g}$ resin). 
<smiles>C=C(C)C(=O)OCC[N+](C)(C)C</smiles><smiles>C=CC(=O)NCNC(=O)C=C</smiles>

Figure 1. Route of synthesis of PCIMETA resin.

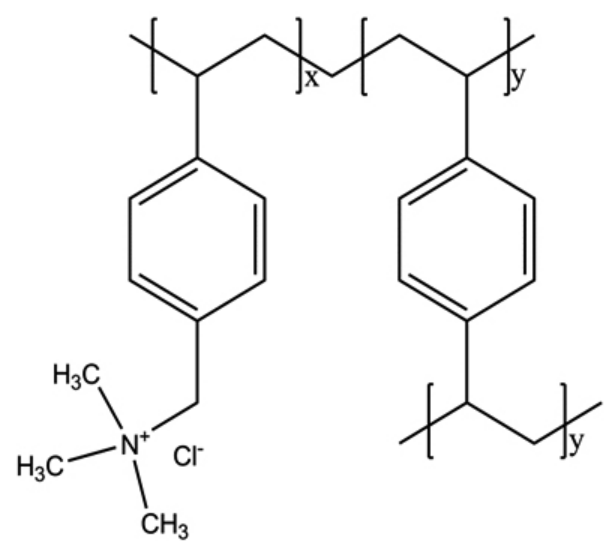

Figure 2. Structure of Amberlite IRA-402 commercial resin.

$$
\text { Degree of swelling }=\frac{\text { Wet } \text { mass of resin }}{\text { Dry } \text { mass of resin }}
$$

\section{Batch Method}

\section{Effect of $\mathbf{p H}$ on the removal}

To study the $\mathrm{pH}$ effect on metal ions removal, solutions of Mo(VI) and $\mathrm{V}(\mathrm{V})$ at $\mathrm{pH}$ values of $2,4,6,8,10$, and 12 were prepared. The $\mathrm{pH}$ values were adjusted with $\mathrm{HNO}_{3}$ and $\mathrm{NaOH}$. The resins $(0.05 \mathrm{~g})$ were contacted with a solution of $50 \mathrm{mg} / \mathrm{L}$ of metal ion in a water bath at constant agitation of 140 rpm for $60 \mathrm{~min}$ and $25^{\circ} \mathrm{C}$. Afterward, the solutions were filtered and washed prior to analysis by atomic absorption spectroscopy (AAS). Thus, the optimum $\mathrm{pH}$ was determined and corresponds to the $\mathrm{pH}$ at which the resin was able to retain the highest amount of the metal ion.

\section{Effect of contact time on the removal}

It was contacted $0.05 \mathrm{~g}$ of PCIMETA resin with $5 \mathrm{~mL}$ of metal ion solution at optimal $\mathrm{pH}$ and keep at $25^{\circ} \mathrm{C}$ with stirring at $140 \mathrm{rpm}$ in a thermodynamic bath. The samples were taken off at 15,30,60, and $120 \mathrm{~min}$. The solutions were filtered and washed prior to AAS analysis.

\section{Maximum retention capacity}

The resin was contacted with $10 \mathrm{~mL}$ of the metal ion solution at optimum $\mathrm{pH}$ with a concentration of $1 \mathrm{~g} / \mathrm{L}$ for $60 \mathrm{~min}$ at $25^{\circ} \mathrm{C}$ with stirring at $140 \mathrm{rpm}$. Finally, the solutions were filtered and washed prior to AAS analysis. The same resin was exposed to a metal ion solution at the same concentration four consecutive times.

Elution

To determine the best eluent $0.05 \mathrm{~g}$ of PCIMETA at maximum retention capacity with $\mathrm{Mo}(\mathrm{VI})$ or $\mathrm{V}(\mathrm{V})$ was used and eluted with $5 \mathrm{~mL}$ of acid solution. It was used hydrochloric and nitric acid at 1 and $4 \mathrm{~mol} / \mathrm{L}$ for $60 \mathrm{~min}$ at 140 $\mathrm{rpm}$ and $25^{\circ} \mathrm{C}$. Then, the solutions were filtered, washed and analyzed by
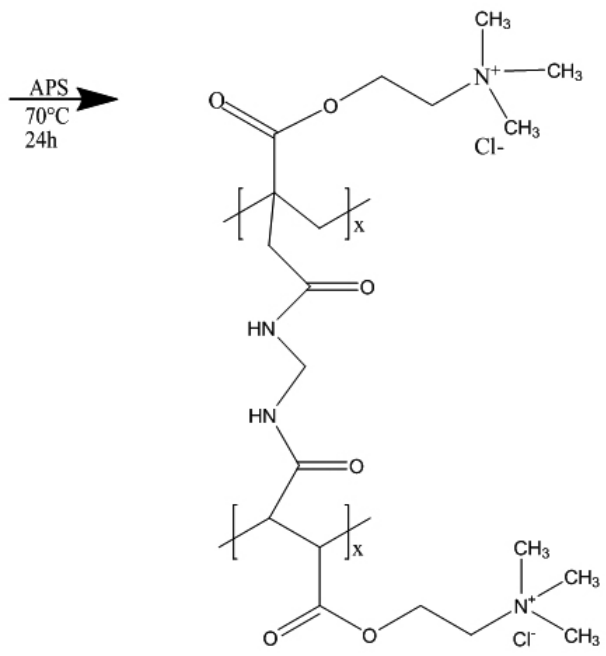

AAS analysis. This procedure was performed separately for each acid with the charged resin.

Regeneration

PCIMETA resin and $10 \mathrm{~mL}$ of metal ion solution were contacted at the optimum $\mathrm{pH}$ for $60 \mathrm{~min}$ at $140 \mathrm{rpm}$ and $25{ }^{\circ} \mathrm{C}$. Then, the solution was filtered and washed. The resin was further discharged of the metal ions using the optimal acid by stirring during $60 \mathrm{~min}$ at $140 \mathrm{rpm}$ and $25{ }^{\circ} \mathrm{C}$ and then was filtered and washed. This cycle of charging and discharging the resin was repeated three consecutive times. The obtained solutions were analyzed by AAS after each step.

Removal under competitive conditions, selectivity

It was prepared a binary solution of $\mathrm{Mo}(\mathrm{VI})$ and $\mathrm{V}(\mathrm{V})$ of $100 \mathrm{mg} / \mathrm{L}$ at $\mathrm{pH} 2$, 4,6 , and 10 . It was contacted $0.04 \mathrm{~g}$ of resin with $10 \mathrm{~mL}$ of the binary solution, and stirred at $140 \mathrm{rpm}$, at $25^{\circ} \mathrm{C}$ during $1 \mathrm{~h}$. After, the solutions were filtered and analyzed by AAS.

Effect of Interferents

Interferent solutions of $100 \mathrm{mg} / \mathrm{L}$ of $\mathrm{Cl}^{-}, \mathrm{PO}_{4}{ }^{3-}$, and $\mathrm{SO}_{4}{ }^{2-}$ were prepared and a solution of $50 \mathrm{mg} / \mathrm{L}$ of metal ion at optimal $\mathrm{pH}$.

$0.04 \mathrm{~g}$ of resin were contacted with $5 \mathrm{~mL}$ of metal ion solution and $5 \mathrm{~mL}$ of interferents, it was kept under stirring at $140 \mathrm{rpm}, 25^{\circ} \mathrm{C}$ during $1 \mathrm{~h}$. After the solutions were filtered and analyzed by AAS.

Thermodynamic studies

For obtain the thermodynamic parameters for PCIMETA an adsorption isotherm study was performed varying the concentration of metal ion at constant mass of resin. The experiment was carried out preparing $25-220 \mathrm{mg} / \mathrm{L}$ of metal ion, the resin mass $(50 \mathrm{mg})$ and the temperature was kept constant with a stirring at $140 \mathrm{rpm}$ during $24 \mathrm{~h}$. Then, the solutions were filtered, washed and were taken for analysis of AAS. The adsorption isotherm was performed at 25, 35 , and $45^{\circ} \mathrm{C}$

The data obtained were adjusted to Langmuir and Freundlich isotherms, and thus to determine if the adsorption of the metal ion in the resin corresponds to a physical or chemical adsorption. The equation (2) and equation (3) show the Langmuir and Freundlich linearized isotherms, respectively.

$$
\text { Langmuir Equation: } \frac{C_{e q}}{X}=\frac{1}{k_{b} X_{m}}+\frac{C_{e q}}{X_{m}}
$$

$\mathrm{C}_{\mathrm{e}}$ : Equilibrium concentration.

$X:$ Amount of metal ion adsorbed per unit weight of the resin.

$\mathrm{X}$ : Maximum adsorption.

$\mathrm{K}_{\mathrm{b}}^{\mathrm{m}}$ : Binding constant.

Freundlich Equation:

$$
\ln (x)=\ln (K)+\frac{1}{n} \ln \left(C_{\text {eq }}\right)
$$

$\mathrm{X}$ : Amount of metal ion adsorbed per unit weight of the resin. $\mathrm{k}$ and $\mathrm{n}$ : Constants.

$\mathrm{C}_{\mathrm{eq}}$ : Equilibrium concentration. 


\section{Column Method}

The column method is a continuous method, where the resin is packed in a column, and the metal ion solution is passing through the column, is here where the process of exchange between the resin and the metal ion occurs, due to the actives sites of the functional groups are in continuous contact with the metal ion solution. The flow of metal ion solution is controlling by a peristaltic pump, for keep a constant flow.

The process of ion exchange by column method has the following steps: column packing, load step, and regeneration step. The column packing consists to introduce the resin inside of the column avoiding bubbles between particles and obtains like this a uniform layer. The load is the step where the ion exchange between the metal ion and the resin occurs. The metal ion solution flow gradually through the column at an optimal flow rate and $\mathrm{pH}$. When the resin starts to saturate, it is observed an increase in the concentration of the effluent in the output current of the column. It is well known as "breakthrough point", that indicates the decrease of the ion exchange capacity of the resin. When the resin lost all their retention capacity the feed entrance is the same of the effluent of the output.

The largest transference of material near to the entrance is in the beginning of the load process, where starts the ion exchange between the resin and the metal ion. As increases the time, the resin more close to the entrance is saturated, and the largest transference occurs in the following area near to the entrance, and so o on, up to reach the end of the column. The region where occurs the largest ion exchange is where is produced a change of concentration, it is called "material transference zone", this zone separate the virgin zone of the saturated.

The time since starts the load up to the metal ion solution appear in the output current, is call "rupture time" (rt). The curve that represents the evolution of the effluent concentration that which lived the bed, is call "breakthrough curve".

The regeneration step consists to return the initial ionic form to the resin, using a concentrate acid solution that removes the retained metal ion. This step is important for the process of ion exchange due to a good operation of the resin in successive process of load will depend of an efficient regeneration.

Retention of metal ions at optimal pH

It was used $100 \mathrm{mg} / \mathrm{L}$ of metal ion solution at optimal $\mathrm{pH}$, determined previously by batch equilibrium procedure. In a glass column $(\mathrm{cm})$ with a porous filter (porous size 100-160 $\mu \mathrm{m}$ ) for support the resin.

It was packed $0.1 \mathrm{~g}$ of hydrated resin. The flow rate was of $9.0 \mathrm{~h}^{-1}$ (space velocity, (SV), L (solution/h)/L resin), and it was collected fractions of $6.0 \mathrm{~mL}$. Afterward, all the fractions were analyzed by AAS.

\section{Column Elution}

It was eluted the packed resin charged with metal ion solution previously. It was used the optimum eluent determined previously by Batch method. It was passing through the column $1000 \mathrm{~mL}$ of an acid solution with a flow rate of 9.0 $\mathrm{h}^{-1}$, and collected fractions of $6.0 \mathrm{~mL}$ for after AAS analyze.

\section{Column Regeneration}

For study the reusability of the resin, 3 cycles of charge-discharge were carried out. This consists in charge the packed resin passing through metal ion solution and after eluted with the optimal acid solution, with a flow rate of 9.0 $\mathrm{h}^{-1}$, and collected fractions of $6.0 \mathrm{~mL}$ for after AAS analyze.

\section{RESULTS AND DISCUSSION}

\section{Characterization of the resin by FT-IR spectroscopy}

The figure 3 shows the FT-IR spectra of PCIMETA resin (black line), where it is possible observe the typical signals of the functional groups at $3431.67 \mathrm{~cm}^{-1} v(\mathrm{~N}-\mathrm{H})$ and $1485.21 \mathrm{~cm}^{-1} v\left(-\mathrm{N}^{+}-\left(\mathrm{CH}_{3}\right)_{3}\right) ; 3015.90 \mathrm{~cm}^{-1} v(-\mathrm{C}-$ $\mathrm{H}) ; 1729.90 \mathrm{~cm}^{-1} v(-\mathrm{C}=\mathrm{O}) ; 1240.47 \mathrm{~cm}^{-1} v(-\mathrm{C}-\mathrm{O})$. It is observed the same absorption signals for PCIMETA resin charged with Mo, but with an increment of intensity.

\section{Scanning Electron Microscopy, SEM}

The shape of particles, rugosity of the surface, and porosity were studied by SEM. It is due to the importance to study the surface characteristic for a material that will be used in adsorption process. A resin with a rough surface will have a higher available surface for interact with an adsorbate.

The SEM analysis of PCIMETA resin was performed with the particle size between 180-250 mm. Figure 4 shows the homogenous particles, with irregular shape, not uniform and without rugosity.

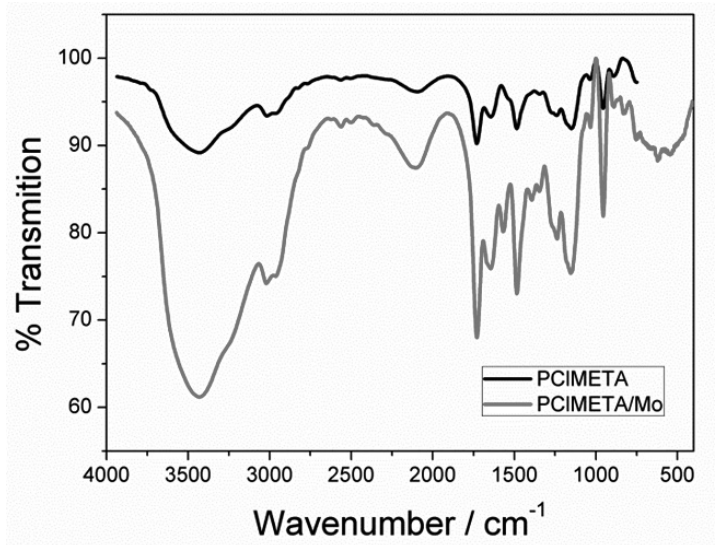

Figure 3. PCIMETA FT-IR spectra in black and PCIMETA charged with Mo in red.
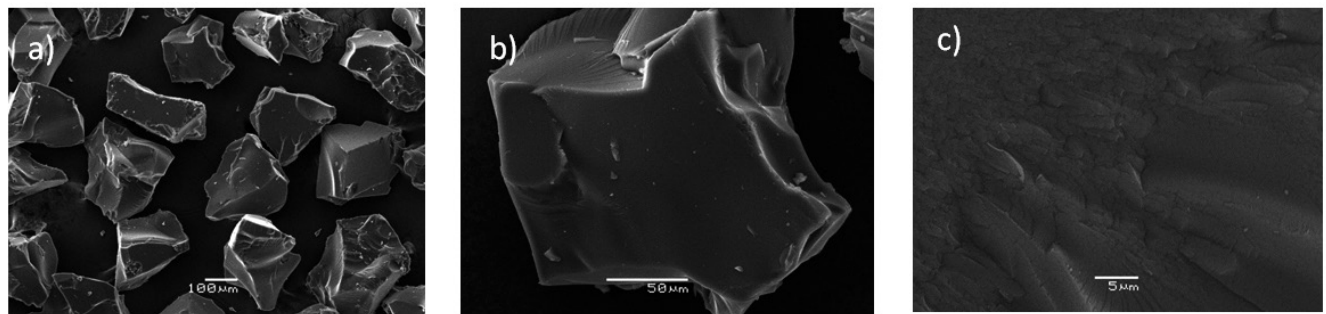

Figure 4. Micrographs of PCIMETA resin at different zooming a) $100 \mathrm{~mm}$, b) $50 \mathrm{~mm}$, and c) $5 \mathrm{~mm}$. Thermogravimetric Analysis, TGA 
In order to obtain the decomposition profile of PCIMETA resin, the resin samples were subjected to control heating. In figure 5 is shown the thermogram of PCIMETA resin, performed under conditions of inert atmosphere and heat rate of $10^{\circ} \mathrm{C} / \mathrm{min}$.

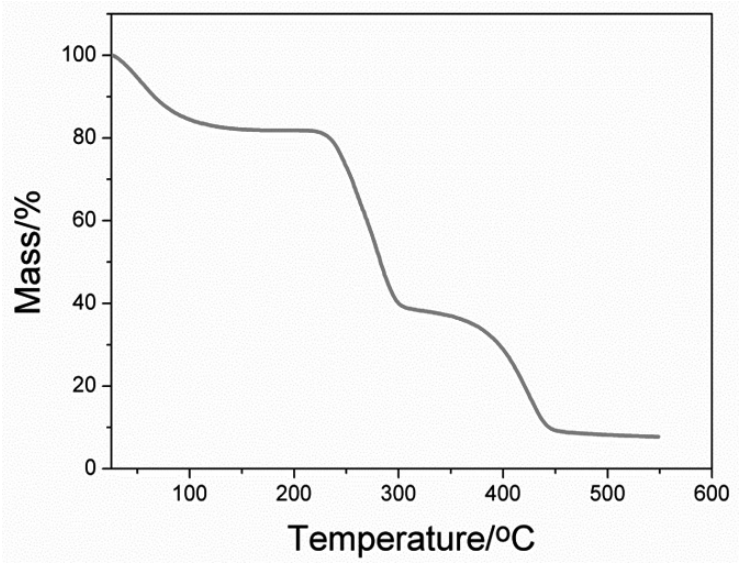

Figure 5. Thermogram of PCIMETA resin.

There is not a significant decomposition temperature. According to the thermogram, of PCIMETA resin is stable up to $250^{\circ} \mathrm{C}$. PCIMETA resin do not show an important loss of weight, attributed probably at water molecules.

Degree of swelling

The degree of swelling is the capacity of water absorption that is direct correlation of the available active sites for removal of metal ions. The degree of swelling is the most important property that in theory allows the metal ions diffuse through the porous crosslinker matrix, favoring the exchange of the metal ions with the functional groups.

The degree of swelling can be influenced by different factors of the polymer matrix structure, like: crosslinking degree, concentration, $\mathrm{pK}$ of ionizable groups, ionization degree, hydrophilicity, among others.

According to the degree of swelling, it is possible to classify the resins in Xerogel ( $0 \mathrm{~g} \mathrm{H}_{2} 0 / \mathrm{g}$ resin) those resins that are not capable to retain water, Hydrogel resins ( 0 to $100 \mathrm{~g} \mathrm{H}_{2} 0 / \mathrm{g}$ resin), are those resins capable to retain water. Exist also the Super Absorbents ( $100 \mathrm{~g} \mathrm{H}_{2} 0 / \mathrm{g}$ resin) that correspond to resins that adsorb higher quantity of water, inhibiting the ion exchange.

Table 1. Degree of swelling for PCIMETA and IRA-402(Cl) resins.

\begin{tabular}{|c|c|}
\hline Resin & Water absorption $\left(\mathrm{g} \mathrm{H}_{2} \mathrm{O} / \mathrm{g}\right.$ resin $)$ \\
\hline PCIMETA & $1.4 \mathrm{~g} \mathrm{H}_{2} \mathrm{O} / \mathrm{g}$ resin \\
\hline IRA-402 $(\mathrm{Cl})$ & $0.69 \mathrm{~g} \mathrm{H}_{2} \mathrm{O} / \mathrm{g}$ resin \\
\hline
\end{tabular}

According to table 1, PCIMETA resin and IRA-402(Cl) commercial resin correspond to hydrogels, but PCIMETA resin have high water absorption capacity than the commercial resin IRA-402(Cl), due to have more available active sites for metal ions removal.

Effect of $\mathrm{pH}$ in the absorption

With the interest to determinate the optimal $\mathrm{pH}$ of absorption, solutions of $\mathrm{Mo}(\mathrm{VI})$ and $\mathrm{V}(\mathrm{V})$ at different $\mathrm{pH}: 2,4,6,8,10$, and 12 at $50 \mathrm{mg} / \mathrm{L}$ of metal ion were prepared.

Molybdenum and vanadium have different speciation depending of the $\mathrm{pH}$ value. The change of $\mathrm{pH}$ will modify the valence of molybdenum and vanadium. Table 2 shows the speciation in function of $\mathrm{pH}$.

Table 2 shows for molybdenum at $\mathrm{pH}$ equal or less than 1, the ions have positive charge, which leads a less possible ion exchange with quaternary ammonium functional groups, but at $\mathrm{pH}$ above 2 will be perfectly possible the remove due to the negative charge of the ion as oxyanion specie, which is favored by the resin structure.

Vanadium at $\mathrm{pH}$ below 2 it is found with positive charge, making less possible the removal by PCIMETA resin due to the quaternary ammonium functional groups, but at values above 2, vanadium is found as oxyanion favoring the ion exchange due to the negative charge.

Effect of $\mathrm{pH}$ on the retention

In Table 3 and 4 are shown the retention of $\mathrm{Mo}(\mathrm{VI})$ and $\mathrm{V}(\mathrm{V})$ in function of $\mathrm{pH}$ for PClMETA and IRA-402(Cl) resins at a $50 \mathrm{mg} / \mathrm{L}$ of concentration.
Both resins showed a high percentage of retention at $\mathrm{pH} 6,8$, and 10 , over $80 \%$, for $\mathrm{Mo}(\mathrm{VI})$ at a concentration of $50 \mathrm{mg} / \mathrm{L}$. It was decided to study at $\mathrm{pH} 6$ for $\mathrm{Mo}(\mathrm{VI})$ removal. Molybdenum at $\mathrm{pH} 6$ is found as $\mathrm{MoO}_{4}{ }^{2-}$.

Table 2. Speciation of molybdenum and vanadium in function of $\mathrm{pH}^{[18]}$

\begin{tabular}{|c|c|c|c|}
\hline \multicolumn{2}{|c|}{ Molybdenum } & Vanadium & \\
\hline $\mathrm{pH}$ & Specie & $\mathrm{pH}$ & Specie \\
\hline$>6.5$ & $\mathrm{MoO}_{4}{ }^{2-}$ & $>13$ & $\mathrm{VO}_{4}{ }^{3-}$ \\
\hline 4.0 & $\mathrm{MoO}_{24}{ }^{6-}$ & 9.0 & $\mathrm{~V}_{2} \mathrm{O}_{7}{ }^{-}$ \\
\hline 2.0 & $\mathrm{Mo}_{8} \mathrm{O}_{26}{ }^{4-}$ & 8.5 & $\mathrm{VO}_{3}{ }^{-}$ \\
\hline$\leq 1$ & $\mathrm{MoO}_{2}{ }^{2+}$ & 6.0 & $\mathrm{~V}_{3} \mathrm{O}_{9}{ }^{3-}$ \\
\hline 0.8 & $\mathrm{MoO}_{3}{ }^{*} \mathrm{H}_{2} \mathrm{O}$ & 2.0 & $\mathrm{~V}_{10} \mathrm{O}_{28}{ }^{6-}$ \\
\hline & & $<2$ & $\mathrm{VO}_{2}{ }^{+}$ \\
\hline
\end{tabular}

Table 3. Retention of $50 \mathrm{mg} / \mathrm{L}$ of $\mathrm{Mo}(\mathrm{VI})$, in function of $\mathrm{pH}$ for PCIMETA and IRA-402(Cl) resins.

\begin{tabular}{|c|c|c|c|c|}
\hline & PCIMETA & & IRA-402(Cl) & \\
\hline $\mathrm{pH}$ & Retention (\%) & $\begin{array}{c}\mathrm{mg} \mathrm{Mo} / \mathrm{g} \\
\text { resin }\end{array}$ & Retention (\%) & $\mathrm{mg} \mathrm{Mo/g} \mathrm{resin}$ \\
\hline 2 & 88.6 & 3.275 & 91.5 & 3.249 \\
\hline 4 & 93.8 & 3.977 & 94.7 & 3.772 \\
\hline 6 & 94.2 & 4.776 & 96.3 & 4.839 \\
\hline 8 & 94,0 & 4.470 & 97.4 & 4.688 \\
\hline 10 & 95.7 & 4.682 & 92.7 & 4.005 \\
\hline 12 & 87.3 & 3.970 & 94.3 & 4.172 \\
\hline
\end{tabular}

For the retention of $50 \mathrm{mg} / \mathrm{L}$ of $\mathrm{V}(\mathrm{V})$ by PClMETA and IRA-402(Cl) resins showed a good performance, retaining over $70 \%$ of the $\mathrm{V}(\mathrm{V})$ at $\mathrm{pH}$ between 4 and 10. It was determined the optimal $\mathrm{pH}$ is $10 \mathrm{for} \mathrm{V}(\mathrm{V})$ removal, at this $\mathrm{pH}$ it is found the specie $\mathrm{V}_{2} \mathrm{O}_{7}^{4-}$.

In general, PCIMETA retain higher amount $\mathrm{V}(\mathrm{V})$ than the commercial resin IRA-402(Cl), at the optimal $\mathrm{pH}$. For $\mathrm{Mo}(\mathrm{VI})$ both retain similar percentage.

Table 4. Retention of $50 \mathrm{mg} / \mathrm{L}$ of $\mathrm{V}(\mathrm{V})$ in function of $\mathrm{pH}$ by PCIMETA and IRA-402 $(\mathrm{Cl})$ resins.

\begin{tabular}{|c|c|c|c|c|}
\hline & PCIMETA & & IRA-402(Cl) & \\
\hline $\mathrm{pH}$ & Retention (\%) & $\begin{array}{c}\mathrm{mg} \mathrm{V/g} \\
\text { resin }\end{array}$ & Retention (\%) & $\mathrm{mg} \mathrm{V/g} \mathrm{resin}$ \\
\hline 2 & 0.00 & 0.000 & 7.30 & 0.4 \\
\hline 4 & 88.7 & 3.923 & 76.4 & 3.3 \\
\hline 6 & 90.9 & 4.002 & 70.0 & 3.2 \\
\hline 8 & 92.3 & 4.821 & 84.5 & 4.1 \\
\hline 10 & 97.7 & 5.135 & 80.7 & 4.5 \\
\hline 12 & 73.8 & 4.038 & 81.1 & 4.6 \\
\hline
\end{tabular}

Effect of contact time on the removal

In table 5 and 6 are shown the percentage of retention and $\mathrm{mg}$ of Mo(VI) or $\mathrm{V}(\mathrm{V})$ per $\mathrm{g}$ of resin at $\mathrm{pH} 6$ and 10 respectively, by PCIMETA and IRA$402(\mathrm{Cl})$ resins. PCIMETA resin reach the equilibrium at around $120 \mathrm{~min}$ for both metal ions, with high retention capacity, $93.2 \%$ and $91.5 \%$ for Mo(VI) and $\mathrm{V}(\mathrm{V})$ respectively. On the other hand, IRA-402(Cl) resin after $120 \mathrm{~min}$ couldn't reach the equilibrium after 120 min, with low retention, $52.4 \%$ and $43.7 \%$ for $\mathrm{Mo}(\mathrm{VI})$ and $\mathrm{V}(\mathrm{V})$ respectively. 
Table 5. Removal of Mo(VI) in function of time by PCIMETA and IRA-402(Cl) resins at $\mathrm{pH} 6$.

\begin{tabular}{|c|c|c|c|c|}
\hline & PCIMETA & IRA-402(Cl) & \\
\hline $\begin{array}{c}\text { Time } \\
(\mathrm{min})\end{array}$ & $\begin{array}{c}\text { Retention } \\
(\%)\end{array}$ & $\begin{array}{c}\mathrm{mg} \mathrm{Mo} / \mathrm{g} \\
\text { resin }\end{array}$ & Retention (\%) & $\begin{array}{c}\mathrm{mg} \mathrm{Mo} / \mathrm{g} \\
\text { resin }\end{array}$ \\
\hline 15 & 78.1 & 2.55 & 21.8 & 0.64 \\
\hline 30 & 92.6 & 3.86 & 44.5 & 1.74 \\
\hline 60 & 88.5 & 3.71 & 41.1 & 1.69 \\
\hline 120 & 93.2 & 3.83 & 52.4 & 2.17 \\
\hline
\end{tabular}

Table 6. Removal of V(V) in function of time by PCIMETA and IRA-402(Cl) resins at pH 10.

\begin{tabular}{|c|c|c|c|c|}
\hline & PCIMETA & IRA-402(Cl) & \\
\hline $\begin{array}{c}\text { Time } \\
(\mathrm{min})\end{array}$ & $\begin{array}{c}\text { Retention } \\
(\%)\end{array}$ & $\mathrm{mg}$ V/g resin & Retention (\%) & $\mathrm{mg} \mathrm{V/g} \mathrm{resin}$ \\
\hline 15 & 46.2 & 2.38 & 0 & 0 \\
\hline 30 & 84.5 & 3.88 & 33.0 & 1.53 \\
\hline 60 & 86.6 & 4.12 & 36.5 & 1.76 \\
\hline 120 & 91.5 & 4.42 & 43.7 & 1.98 \\
\hline
\end{tabular}

Maximum retention capacity

In table 7 are shown the percentages of retention and the maximum retention capacity values obtained by successive enrichment of the PClMETA resin at pH 6 and 10, for $\mathrm{Mo}(\mathrm{VI})$ and $\mathrm{V}(\mathrm{V})$ respectively

Table 7. Maximum retention capacity of PCIMETA resin with Mo(VI) and V(V) ions.

\begin{tabular}{|c|c|c|c|c|c|c|c|c|}
\hline Resin & $\begin{array}{c}\text { Metal } \\
\text { ion }\end{array}$ & No cycle & $\begin{array}{c}\text { Retained } \\
\text { mass } \\
(\mathrm{mg})\end{array}$ & $\begin{array}{c}\text { Mass } \\
\text { resin (g) }\end{array}$ & $\begin{array}{c}\text { Mass ret. (mg/g } \\
\text { resin) }\end{array}$ & $\begin{array}{c}\mathrm{R} \\
(\%)\end{array}$ & $\begin{array}{c}\text { Total mass } \\
\text { retained } \\
(\mathrm{mg})\end{array}$ & $\begin{array}{c}\text { Total mass } \\
\text { retained } \\
(\mathrm{mg} / \mathrm{g} \text { resin) }\end{array}$ \\
\hline PCIMETA & Mo(VI) & 2 & 9.100 & 0.470 & 19.35 & 98.3 & 18.25 & 38.82 \\
\hline & & 3 & 8.997 & & 19.13 & 97.2 & 27.25 & 57.95 \\
\hline & & 4 & 8.805 & & 18.72 & 95.1 & 36.06 & 76.67 \\
\hline & & 1 & 9.40 & & 19.63 & 98.5 & 9.40 & 18.87 \\
\hline PCIMETA & $\mathrm{V}(\mathrm{V})$ & 2 & 9.40 & 0.479 & 19.63 & 98.5 & 18.81 & 37.75 \\
\hline & & 3 & 9.47 & & 19.77 & 99.3 & 28.29 & 56.77 \\
\hline & & 4 & 9.50 & & 19.83 & 99.6 & 37.79 & 75.85 \\
\hline
\end{tabular}

*It is was used $500 \mathrm{mg}$ of resin with an aliquot of $10 \mathrm{~mL}$ of metal ion $1000 \mathrm{mg} / \mathrm{L}$ of concentration, stirring at $140 \mathrm{rpm}$, during $1 \mathrm{~h}$ at $25^{\circ} \mathrm{C}$.

Table 7 shows that PCIMETA resin have a high maximum retention capacity, and start to saturate with the consecutives cycles, but could continue being charged with metal ion solution at the optimal $\mathrm{pH}$ and contact time. These results suggest that the resin could be used in continuous process as column method.

Acid Elution

Table 8 shows the elution with different acids for PCIMETA resin in contact with $\mathrm{Mo}(\mathrm{VI})$ and $\mathrm{V}(\mathrm{V})$ ions.

Table 8. Elution of PCIMETA resin with different acids for Mo(VI) and $\mathrm{V}(\mathrm{V})$ ions.

\begin{tabular}{|c|c|c|c|c|c|}
\hline & & & $\begin{array}{c}\text { Elution } \\
(\%)\end{array}$ & & \\
\hline Resin & Metal ion & $1 \mathrm{M} \mathrm{HCl}$ & $4 \mathrm{M} \mathrm{HCl}$ & $1 \mathrm{M} \mathrm{HNO}_{3}$ & $4 \mathrm{M} \mathrm{HNO}_{3}$ \\
\hline PClMETA & $\mathrm{Mo}(\mathrm{VI})$ & 65.5 & 99.0 & 58.9 & 57.7 \\
\hline & $\mathrm{V}(\mathrm{V})$ & 74.1 & 99.0 & 85.8 & 84.1 \\
\hline
\end{tabular}

According with the results of table 8 , the best eluent for both metal ions is $4 \mathrm{M} \mathrm{HCl}$ solution, removed $99.0 \%$ of $\mathrm{Mo}(\mathrm{VI})$ and $\mathrm{V}(\mathrm{V})$ ions.

\section{Regeneration}

This study was performed with a solution $1000 \mathrm{mg} / \mathrm{L}$ of metal ion at the optimal $\mathrm{pH}, 6$ and 10 for $\mathrm{Mo}(\mathrm{VI})$ and $\mathrm{V}(\mathrm{V})$ respectively. It was carried out on 3 consecutives cycles of charge-discharge. For the discharge was used the optimal acid for elution, $4 \mathrm{M} \mathrm{HCl}$ solution. In figure 6 we can observe the profile of regeneration for PCIMETA resin. For molybdenum in the first cycle $95.1 \%$ was retained, and discharged a $99.0 \%$. In the second cycle decreased the retention, $74.0 \%$, but the resin still maintaining the capacity to retain metal ions, but the second discharge decreased considerable, just elute $45.0 \%$. The resin start to lose the capacity to retain, and in the third cycle the retention decreased even more, $65.9 \%$, and discharge just of $27.8 \%$.

For vanadium it is possible observe that the regeneration is less efficient in comparison with molybdenum. In the first cycle retain $66.0 \%$ and discharge $99.0 \%$, in the second cycle this values decrease at $32.0 \%$ of charge and $60.0 \%$ of discharge. Finally, in the third cycle decreases strongly to $25.4 \%$ of retention and $32.6 \%$ of discharge. The decrease of the regeneration in consecutives cycles could be because not all of the metal ions were removed from the resin in earlier cycles, and some amount of metal ions remained trapped inside the pores of the resin. 


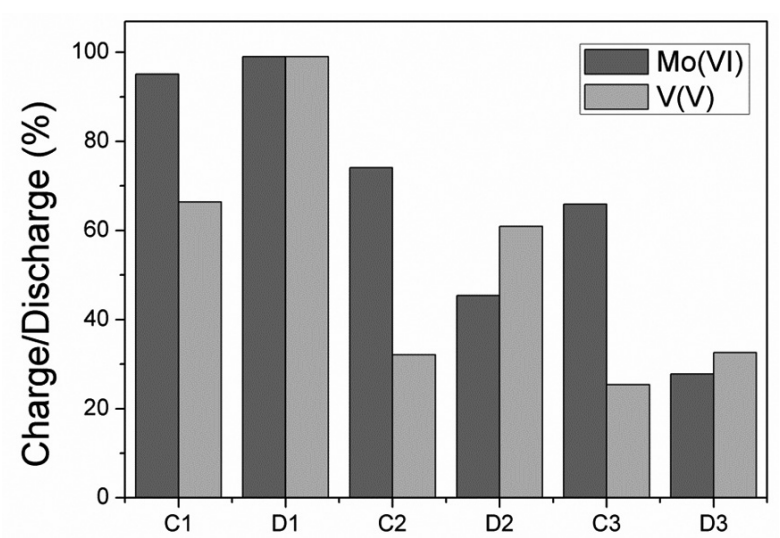

Figure 6. Regeneration profile of PCIMETA resin with $\mathrm{Mo}(\mathrm{VI})$ and $\mathrm{V}(\mathrm{V})$ ions at $\mathrm{pH} 6$ and 10 respectively.

\section{Selectivity}

Table 9 shows the selectivity in binary mixture of $\mathrm{Mo}(\mathrm{VI})-\mathrm{V}(\mathrm{V})$ ions at $\mathrm{pH}$ 6 and 10.Is observed at both $\mathrm{pH}$, that $\mathrm{V}(\mathrm{V})$ has higher retention than $\mathrm{Mo}(\mathrm{VI})$. PCIMETA resin is more selective for $\mathrm{V}(\mathrm{V})$ ions in a binary mixture of $\mathrm{Mo}(\mathrm{VI})$ $\mathrm{V}(\mathrm{V})$ at $\mathrm{pH} 6$ and 10.

The selectivity was studied according to $\mathrm{D}_{\mathrm{i}}$ the distribution coefficient for a metal ion, $\mathrm{K}_{\mathrm{ij}}$ is the selectivity coefficient that gives information about the affinity of the resin for metal ion or other. Equations 4 and 5 .

$$
\begin{gathered}
D_{i}=\frac{M_{i, R}}{M_{i, S}} \times \frac{V_{s}}{m_{R}} \\
K_{i, j}=\frac{D_{i}}{D_{j}}
\end{gathered}
$$

Table 9. Selectivity from binary mixture of $\mathrm{Mo}(\mathrm{VI})-\mathrm{V}(\mathrm{V})$ at $\mathrm{pH} 6$ and 10.

\begin{tabular}{|c|c|c|c|c|c|}
\hline Metal Ion & $\mathrm{pH}$ & $\begin{array}{c}\text { Mass } \\
\text { retained } \\
(\mathrm{mg})\end{array}$ & $\begin{array}{c}\text { Mass } \\
\text { retained } \\
(\mathrm{mg} / \mathrm{g} \text { resin) }\end{array}$ & $\begin{array}{c}\text { Retention } \\
(\%)\end{array}$ & $\mathrm{K}_{\mathrm{Mo} / \mathrm{V}}$ \\
\hline $\mathrm{Mo}(\mathrm{VI})$ & 6 & 0.362 & 8.58 & 74.9 & 0.86 \\
\hline $\mathrm{V}(\mathrm{V})$ & 6 & 0.422 & 5.20 & 94.3 & \\
\hline $\mathrm{Mo}(\mathrm{VI})$ & 10 & 0.303 & 7.08 & 66.1 & 0.63 \\
\hline $\mathrm{V}(\mathrm{V})$ & 10 & 0.481 & 6.00 & 97.9 & \\
\hline
\end{tabular}

According to the coefficients of affinity $\mathrm{K}_{\mathrm{Mo} / \mathrm{V}}$, PCIMETA resin has low affinity for Mo(VI) ions, because the value is below of 1 .

\section{Effect of the interferents}

It was studied the removal properties of $\mathrm{V}(\mathrm{V})$ by PCIMETA resin in presence of the interferents $\mathrm{Cl}^{-}, \mathrm{PO}_{4}^{3-}$, and $\mathrm{SO}_{4}^{2-}$, because they are the principal anions found in water. In table 10 is possible to observe that the presence of these anions decrease dramatically the retention of $\mathrm{V}(\mathrm{V})$ by PCIMETA resin, this mean that $\mathrm{Cl}^{-}, \mathrm{PO}_{4}^{3-}$, and $\mathrm{SO}_{4}^{2-}$ anions compete with the $\mathrm{V}(\mathrm{V})$ ion for the active sites of PCIMETA resin, due to the electrostatic forces produced by their ionic form.

The $\mathrm{Cl}^{-}, \mathrm{PO}_{4}^{3-}$, and $\mathrm{SO}_{4}^{2-}$ anions influence in different form depending of their speciation in front of the metal ion. It is well known that the resins with anionic exchange groups prefer multivalent ions than the monovalent, which affects proportionally the electrostatic force.

\section{Thermodynamic studies}

Adsorption isotherms give important information about the adsorption process and the interaction between the resins (adsorbent) with the metal ions (adsorbate). In figure 7 is observed the adsorption behavior of PCIMETA resin with $\mathrm{Mo}(\mathrm{VI})$ at $\mathrm{pH} 6$ and 10, at $\mathrm{pH} 10$ PCIMETA resin has higher retention capacity than at $\mathrm{pH} 6$ for $\mathrm{Mo}(\mathrm{VI})$, but at $\mathrm{pH} 6$ reached the equilibrium before that at $\mathrm{pH} 10$.
Table 10. Removal of $\mathrm{V}(\mathrm{V})$ in presence of interferents at $\mathrm{pH} 10$.

\begin{tabular}{|c|c|c|c|}
\hline Interferents & $\begin{array}{c}\text { Mass retained } \\
(\mathrm{mg})\end{array}$ & $\begin{array}{c}\text { Mass retained } \\
(\mathrm{mg} / \mathrm{g} \text { resin) }\end{array}$ & $\begin{array}{c}\text { Retention } \\
(\%)\end{array}$ \\
\hline $\mathrm{Cl}^{-}$ & 0.028 & 0.694 & 12.0 \\
\hline $\mathrm{PO}_{4}{ }^{3-}$ & 0.025 & 0.619 & 10.7 \\
\hline $\mathrm{SO}_{4}^{2-}$ & 0.015 & 0.382 & 6.50 \\
\hline
\end{tabular}

* It was used $50 \mathrm{mg} / \mathrm{L}$ of $\mathrm{V}(\mathrm{V})$ and $100 \mathrm{mg} / \mathrm{L}$ of each interferent.

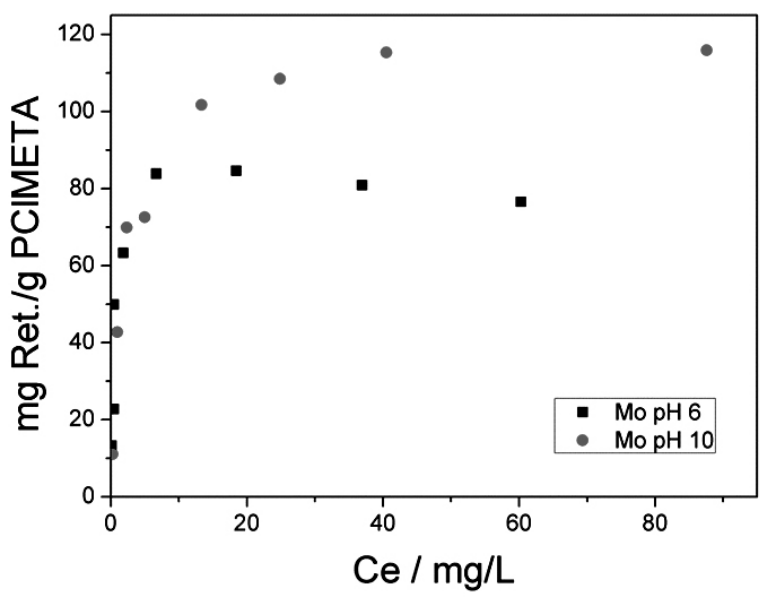

Figure 7. Adsorption isotherm for PCIMETA resin with $\mathrm{Mo}(\mathrm{VI})$ at $\mathrm{pH} 6$ and 10 .

The figure 7 shows that at constant temperature $\left(25^{\circ} \mathrm{C}\right)$ and gradually increase of the concentration of $\mathrm{Mo}(\mathrm{VI})$ exist a higher retention at higher concentrations at $\mathrm{pH} 10$, at lower concentrations there is not difference between pH 6 or 10 .

The isotherm constants summarized in table 11 show a better correlation for Langmuir than Freundlich for Mo(VI) and V(V) ions. These results suggest that exists formation of monolayer. The Langmuir constant "b", do not show a clear trend of adsorption for IRA-402 $(\mathrm{Cl})$ resin. This constant has a direct relation with the affinity between resin/metal ion and the maximum retention capacity. PCIMETA resin shows a high constant of Langmuir with a high maximum capacity of retention $(76.92 \mathrm{mg} \mathrm{Mo} / \mathrm{g}$ resin and $158.73 \mathrm{mg}$ $\mathrm{V} / \mathrm{g}$ resin), suggesting a high affinity resin/metal ion under the experimental conditions of $\mathrm{pH} 6$ and 10 for $\mathrm{Mo}(\mathrm{VI})$ and $\mathrm{V}(\mathrm{V})$, respectively, at $25^{\circ} \mathrm{C}$.

After were performed adsorption isotherms for PCIMETA resin at different temperatures with $\mathrm{Mo}(\mathrm{VI})$ and $\mathrm{V}(\mathrm{V})$ at $\mathrm{pH} 6$ and 10 . The results are shown in Figure 8.

(a)

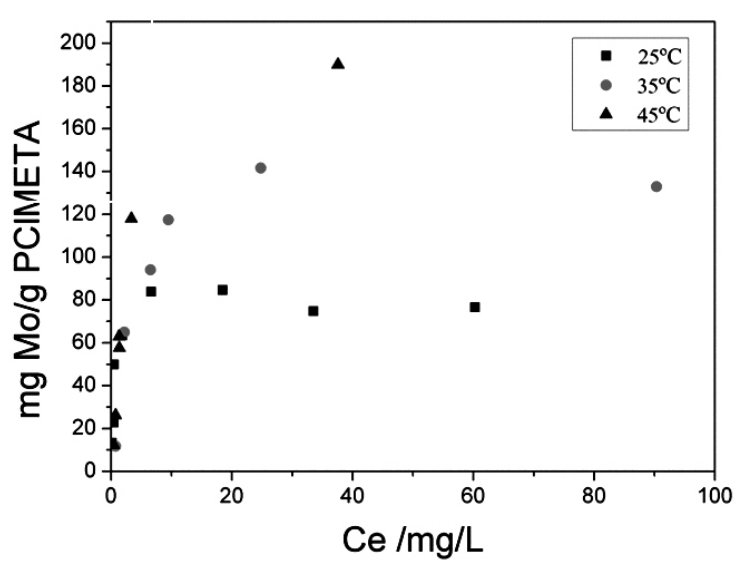


(b)

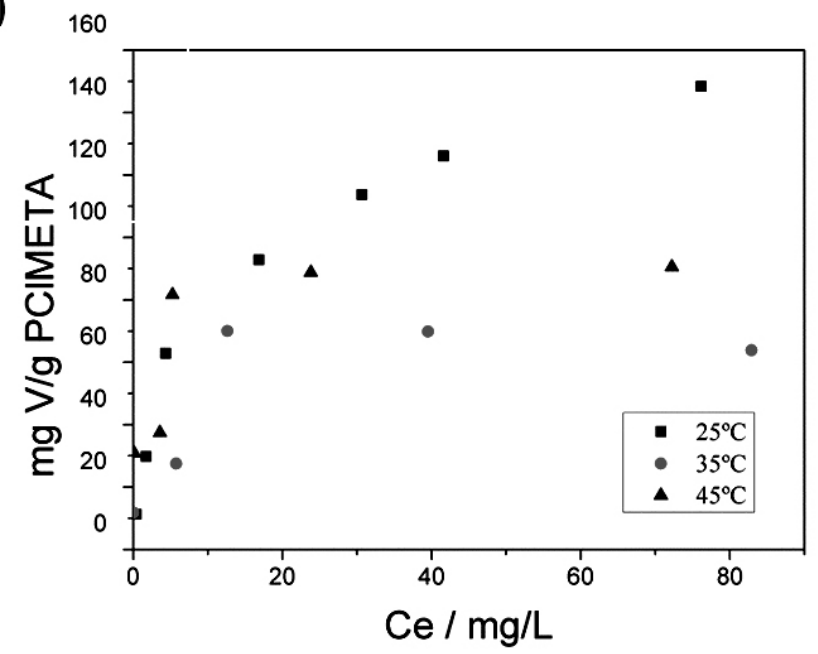

Figure 8. Isotherms for PCIMETA resin with (a) Mo(VI) and (b) V(V), in function of the temperature.

Table 11. Constants of isotherms of Langmuir and Freundlich for $\mathrm{Mo}(\mathrm{VI})$ and $\mathrm{V}(\mathrm{V})$ ions at $\mathrm{pH} 6$ and 10, respectively, at $25^{\circ} \mathrm{C}$.

\begin{tabular}{|c|c|c|c|c|c|c|c|}
\hline & & Langmuir & & & Freundlich & \\
\hline Resin & $\begin{array}{c}\text { Metal } \\
\text { ion }\end{array}$ & $\begin{array}{c}\mathrm{qm}(\mathrm{mg} \mathrm{Mo} / \mathrm{g} \\
\text { resin) }\end{array}$ & $\mathrm{b}(\mathrm{L} / \mathrm{mg})$ & $\mathrm{R}^{2}$ & $\mathrm{~N}$ & $\begin{array}{c}\mathrm{K}_{\mathrm{f}}(\mathrm{mg} \mathrm{Mo} / \mathrm{g} \\
\text { resin) }\end{array}$ & $\mathrm{R}^{2}$ \\
\hline PClMETA & $\mathrm{Mo}(\mathrm{VI})$ & 76.92 & 6.19 & 0.9983 & 3.93 & 37.43 & 0.7088 \\
\hline & $\mathrm{V}(\mathrm{V})$ & 158.73 & 0.1177 & 0.9881 & 2.075 & 21.968 & 0.9596 \\
\hline IRA-402(Cl) & $\mathrm{Mo}(\mathrm{VI})$ & 400 & 0.0059 & 0.9393 & 3.47 & 19.5 & 0.531 \\
\hline & $\mathrm{V}(\mathrm{V})$ & 126.58 & 0.103 & 0.9961 & 1.829 & 15.538 & 0.9691 \\
\hline
\end{tabular}

In figure 8.(a) is observed an influence in the retention of $\mathrm{Mo}(\mathrm{VI})$ with the temperature, with an increase of temperature is observe an increase of retention capacity. This can be probably due to an increase of the kinetic energy of metal ions, favoring the diffusion to the metal ions through the active sites of the resin. For $\mathrm{V}(\mathrm{V})$ we can observe in figure 8.(b) that the temperature affect in different form the adsorption showed a totally opposite trend than for Mo(VI), there is a higher adsorption at $25^{\circ} \mathrm{C}$.

Langmuir constants of PCIMETA resin with $\mathrm{Mo}(\mathrm{VI})$ and $\mathrm{V}(\mathrm{V})$ at different temperatures were calculated in order to determine the thermodynamic parameters. The results are shown in table 12.

Table 12. Constants of Langmuir in function of temperature for PCIMETA resin charged with $\mathrm{Mo}(\mathrm{VI})$ and $\mathrm{V}(\mathrm{V})$ at $\mathrm{pH} 6$ and 10 , respectively.

\begin{tabular}{|c|c|c|c|c|}
\hline & & \multicolumn{2}{|c|}{ Langmuir Constants } & \\
\hline $\begin{array}{c}\text { Temperature } \\
\left({ }^{\circ} \mathrm{C}\right)\end{array}$ & Metal ion & $\begin{array}{c}\mathrm{q}_{\mathrm{m}}(\mathrm{mg} \mathrm{Mo} / \mathrm{g} \\
\mathrm{P}(\mathrm{ClMETA})\end{array}$ & $\begin{array}{c}\mathrm{b} \\
(\mathrm{L} / \mathrm{mg})\end{array}$ & $\mathrm{R}^{2}$ \\
\hline 25 & $\mathrm{Mo}(\mathrm{VI})$ & 76.923 & 61.904 & 0.9983 \\
\hline & $\mathrm{V}(\mathrm{V})$ & 158.73 & 0.1177 & 0.9881 \\
\hline 35 & $\mathrm{Mo}(\mathrm{VI})$ & 138.88 & 0.3100 & 0.9933 \\
\hline 45 & $\mathrm{~V}(\mathrm{~V})$ & 66.670 & 0.4934 & 0.9863 \\
\hline & $\mathrm{Mo}(\mathrm{VI})$ & 212.76 & 0.2338 & 0.9911 \\
\hline & $\mathrm{V}(\mathrm{V})$ & 93.450 & 0.5240 & 0.9956 \\
\hline
\end{tabular}

With the data of Table 12 it is possible calculate the thermodynamic parameters, like free energy of Gibbs $\Delta \mathrm{G}^{\circ}$, enthalpy $\Delta \mathrm{H}^{\circ}$, and entropy DS . The free energy $\Delta \mathrm{G}^{\circ}$ is determined with the equation (6), and using the constant of Langmuir.

$$
\Delta G^{\circ}=-R T \ln b
$$

The Enthalpy and Entropy, $\Delta \mathrm{H}^{\circ}$ and $\mathrm{DS}^{\circ}$ can be obtained with the relation of Van't Hoff given by the equation (7).

$$
\log (b)=\frac{\Delta S^{\circ}}{2.303 R}-\frac{\Delta H^{\circ}}{2.303 R T}
$$

A graph of $\log (\mathrm{b})$ vs. $1 / \mathrm{T}$ allow determine $\Delta \mathrm{H}^{\circ}$ andDS ${ }^{\circ}$ from the slope and the intercept, respectively. 
Table 13. Thermodynamic parameters for PCIMETA resin with Mo(VI) and $\mathrm{V}(\mathrm{V})$ at $\mathrm{pH} 6$ and 10 , respectively.

\begin{tabular}{|c|c|c|c|c|}
\hline $\begin{array}{c}\mathrm{T} \\
{[\mathrm{K}]}\end{array}$ & Metal ion & $\begin{array}{c}\Delta \mathrm{G}^{\circ} \\
{[\mathrm{kJ} / \mathrm{mol}]}\end{array}$ & $\begin{array}{c}\Delta \mathrm{H}^{\circ} \\
{[\mathrm{kJ} / \mathrm{mol}]}\end{array}$ & $\begin{array}{c}\mathrm{DS}^{\circ} \\
{[\mathrm{kJ} / \mathrm{mol}]}\end{array}$ \\
\hline 298.15 & $\mathrm{Mo}(\mathrm{VI})$ & -4.52 & & \\
\hline & $\mathrm{V}(\mathrm{V})$ & 5.30 & & \\
\hline 308.15 & $\mathrm{Mo}(\mathrm{VI})$ & 3.00 & -130.33 & -0.43 \\
\hline & $\mathrm{V}(\mathrm{V})$ & 1.81 & 59.46 & 0.18 \\
\hline 318.15 & $\mathrm{Mo}(\mathrm{VI})$ & 3.84 & & \\
\hline & $\mathrm{V}(\mathrm{V})$ & 1.71 & & \\
\hline
\end{tabular}

The table 13 summarizes the values of $\Delta \mathrm{G}^{\circ}, \Delta \mathrm{H}^{\circ}$, and $\mathrm{DS}^{\circ}$ obtained for the adsorption of $\mathrm{Mo}(\mathrm{VI})$ and $\mathrm{V}(\mathrm{V})$ by PCIMETA resin. The values of free energy depend considerable by the temperature, at $285.5 \mathrm{~K}$ there is a negative value for the adsorption of $\mathrm{Mo}(\mathrm{VI})$, this is mean that the adsorption process is spontaneous, and by increasing the temperature the values are more positive, that is that at high temperature the process of adsorption is not spontaneous. This is corroborated with the low constants of Langmuir previously obtained. For the adsorption of $\mathrm{V}(\mathrm{V})$ the process is not spontaneous at the temperatures studied.

The enthalpy suggests an exothermic process for Mo(VI), the adsorption releases heat. For the adsorption of $\mathrm{V}(\mathrm{V})$ the process is endothermic, we need to deliver energy to the system.

The values of entropy for Mo(VI) suggest a decrease of the degrees of freedom, due to the metal ion is retained by the PCIMETA resin, and passing to a more organized state. By other side, the adsorption of $\mathrm{V}(\mathrm{V})$ suggests an increase of the randomness (increase of the number of species) in the resin surface.

Study of the retention of Mo(VI) and V(V) by Column Method

The analysis of the retention for Mo(VI) and V(V) was carried out by the calculation of area of the breakthrough curve to determine the mass retained by the resin, and the retention capacity, using the following equations:

Mass retained $(\mathrm{mg})$ :

$$
m_{r}=A_{b r} * C_{o}
$$

Retention capacity of PCIMETA resin:

$$
q_{o}=\frac{A_{b r} * C_{o}}{g_{\text {resin }}}
$$

$\mathrm{m}_{\mathrm{r}}$ : milligrams retained

$\mathrm{A}_{\mathrm{br}}:$ area of Breakthrough curve

$\mathrm{C}_{\mathrm{b}}$ : initial concentration of metal ion

$\mathrm{q}_{0}:$ PCIMETA resin retention capacity

$\mathrm{g}_{\text {resin }}$ : grams of packed resin

Table 14 shows for $\mathrm{V}(\mathrm{V})$ different breakthrough point for the 3 cycles, and different retentions also. The first cycle was the higher retention $(4738.58 \mathrm{mg} / \mathrm{g}$ PCIMETA , the profile of figure 9.a corroborates that, where it is possible observe a low breakthrough point, that is mean the retention is efficient. For the second cycle of charge the breakthrough point decreases, therefore, the efficiency and the capacity also decreased $\left(1954.33 \mathrm{mg} / \mathrm{g}_{\mathrm{PCIMETA}}\right)$. In the third cycle of charge decrease even more the breakthrough point, and the efficiency and capacity till $\left(1497.42 \mathrm{mg} / \mathrm{g}_{\text {PCIMETA }}\right)$.

For Mo(VI) were performed just 2 cycles of charge, for check if follows the same behavior of $\mathrm{V}(\mathrm{V})$. In figure $9 . \mathrm{b}$ we can observe that PCIMETA resin has high retention capacity in the first cycle of charge $(8030.2 \mathrm{mg} \mathrm{Mo} / \mathrm{g}$ PCIMET), PCIMETA resin have the double of efficiency for remove Mo(VI) ion than for $\mathrm{V}(\mathrm{V})$. In the second cycle of charge the breakthrough point change dramatically, decreasing significantly the efficiency and retention capacity (4042.0 mg Mo/ $\mathrm{g}_{\text {PCIMETA }}$ ), for this reason is decide do not do a third cycle. The calculated data are shown in table 14. (a)

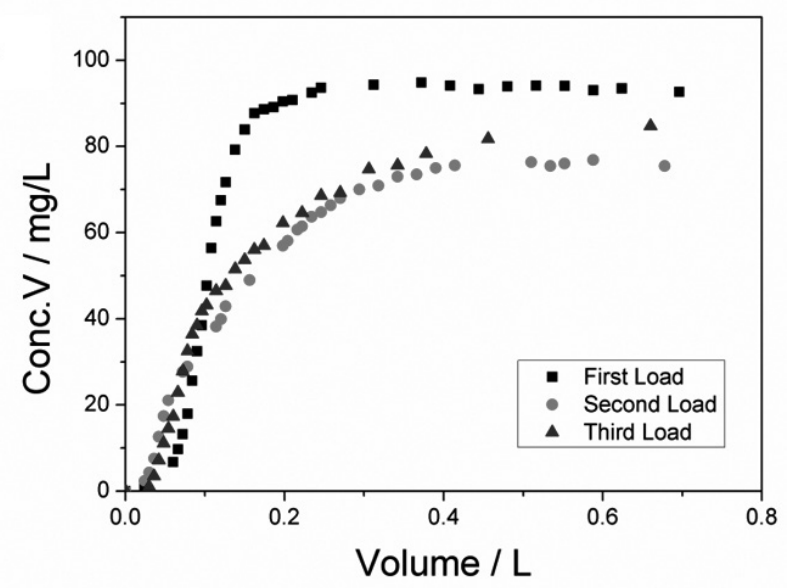

(b)

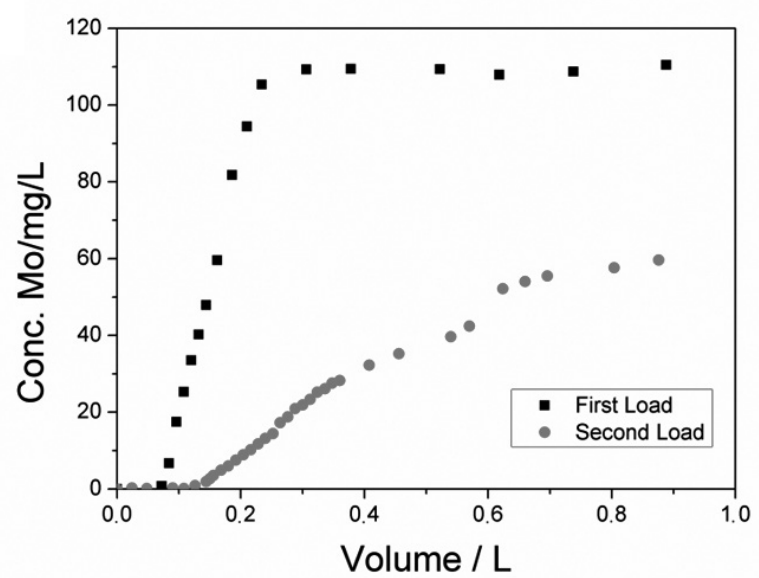

Figure 9. Adsorption profile for PCIMETA resin with (a) V(V) and (b) $\mathrm{Mo}(\mathrm{VI})$ solution, at $\mathrm{pH} 10$ and 6 , respectively.

Table 14. Data of Column method study for PCIMETA resin with Mo(VI) and $\mathrm{V}(\mathrm{V})$ ions.

\begin{tabular}{|c|c|c|c|c|}
\hline Metal ion & Load & $\begin{array}{c}\text { Breakthrough } \\
\text { point }\end{array}$ & $\begin{array}{c}\text { Mass retained } \\
(\mathrm{mg})\end{array}$ & $\begin{array}{c}\text { Resin capacity } \\
(\mathrm{mg} / \mathrm{g} \text { resin) }\end{array}$ \\
\hline & $1^{\circ}$ & 5.14 & 475.75 & 4738.58 \\
\hline $\mathrm{V}(\mathrm{V})$ & $2^{\circ}$ & 2.59 & 196.21 & 1954.33 \\
\hline & $3^{\circ}$ & 2.06 & 150.34 & 1497.42 \\
\hline $\mathrm{Mo}(\mathrm{VI})$ & $1^{\circ}$ & 7.78 & 807.04 & 8038.2 \\
\hline & $2^{\circ}$ & 7.50 & 405.82 & 4042.0 \\
\hline
\end{tabular}

\section{Column Elution}

For the column elution was used the optimal acid used in Batch method, $4 \mathrm{M} \mathrm{HCl}$. PCIMETA resin was regenerate after every cycle of charge. The regeneration was efficient and fast.

In figure 10 is shown the elution of $\mathrm{V}(\mathrm{V})$ from the column, the first discharge is the most efficient, was removed almost all the $V(V)$, in black. In the second cycle was removed the remained $\mathrm{V}(\mathrm{V})$ ion, in red. Finally, the equilibrium was reached with the third cycle of discharge $(4.287 \mathrm{mg} \mathrm{V} / \mathrm{L})$ the acid do not remove more metal ion, in blue.

The elution of Mo(VI) was very efficient, the profile of elution is shown in figure 11. In the first cycle of discharge the concentration of $\mathrm{Mo}(\mathrm{VI})$ decreases abruptly, it was removed practically all the Mo(VI) (see black points in figure). In the second discharge cycle was reaching a equilibrium of discharge, the acid do not remove more Mo(VI) (see red point in figure). For this reason do not was continued a third discharge. 


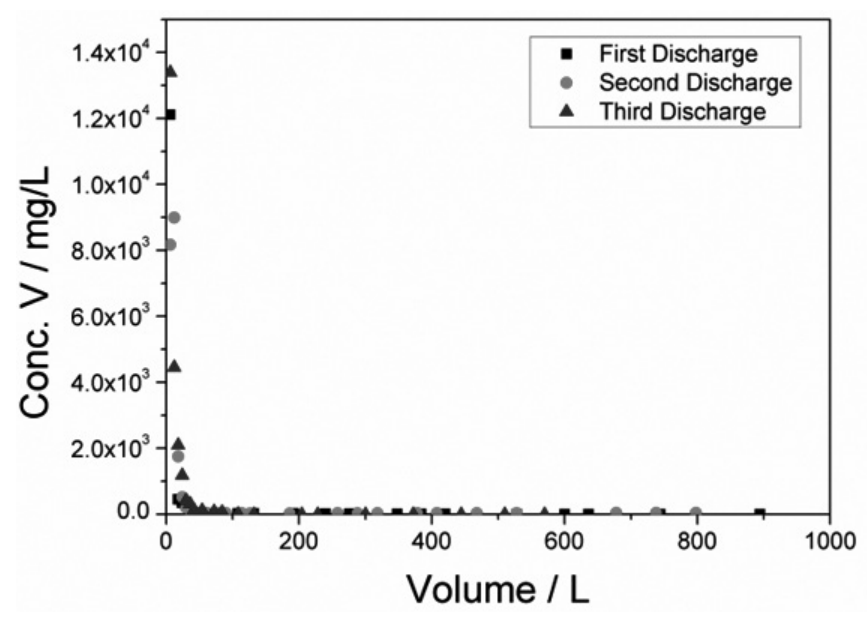

Figure 10. Elution of PCIMETA resin in column charged with $V(V)$ with $4 \mathrm{M} \mathrm{HCl}$.

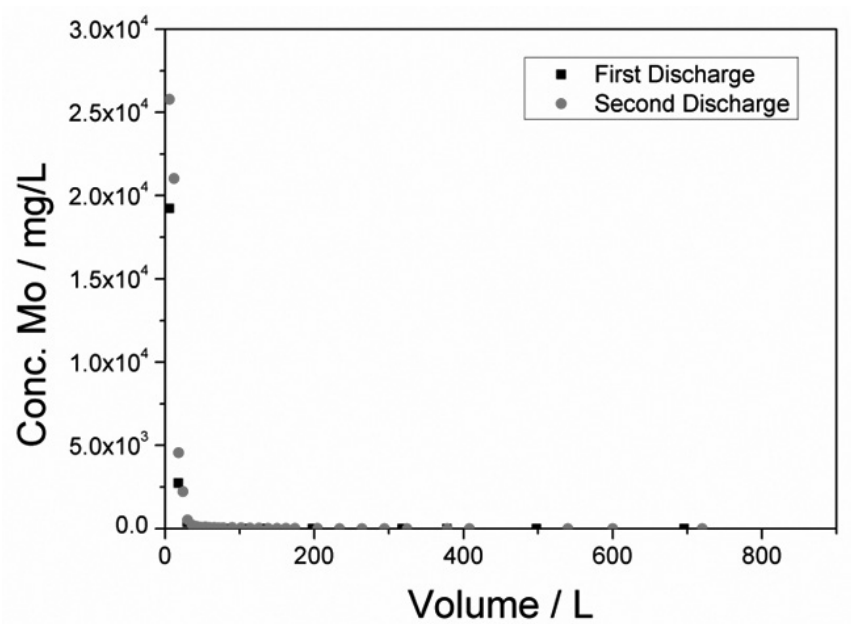

Figure 11. Elution of PCIMETA resin in column charged with Mo(VI) with $4 \mathrm{M} \mathrm{HCl}$.

\section{CONCLUSIONS}

It was successful synthesized PCIMETA resin with ammonium quaternary groups available for adsorption of anions. PCIMETA resin is a good ion exchange resin for $\mathrm{Mo}(\mathrm{VI})$ and $\mathrm{V}(\mathrm{V})$ anions at $\mathrm{pH} 6$ and 10, respectively, by Batch method. PCIMETA resin remove these metal ions fast (before than $1 \mathrm{~h}$ ) by Batch method, and even more efficient than the commercial resin Amberlite IRA-402(Cl) with the same functional groups. It is possible regenerate the PCIMETA resin using $4 \mathrm{M} \mathrm{HCl}$ for both metal ions.

Adsorption isotherms demonstrate the adsorption is by monolayer, and both metal ions follows the Langmuir Model. Thermodynamic parameters shows both metal ions flows different process of adsorption by the resin, the adsorption of $\mathrm{Mo}(\mathrm{VI})$ is spontaneous and exothermic, meanwhile the adsorption of $\mathrm{V}(\mathrm{V})$ is not spontaneous and endothermic.

PCIMETA resin can be used in a continuous system by Column method. The resin shows high retention capacity in continuous system for $\mathrm{Mo}(\mathrm{VI})$ and $\mathrm{V}(\mathrm{V})$ but show to be more efficient for remove Mo(VI) than $\mathrm{V}(\mathrm{V})$ in continuous system. The column was efficiently regenerated by $4 \mathrm{M} \mathrm{HCl}$ in 3 consecutive cycles for $\mathrm{V}(\mathrm{V})$ and 2 cycles for Mo(VI). The success in the use of PCIMETA resin by Column method confirmed that could be used in a continuous process.

\section{REFERENCES}

1. B. Barkhordar, M. Ghiasseddi, J. Environ. Health Sci. Eng., 1: 58-64 (2004).

2. D. Prabhakaran, M.S. Subramanian, Talanta, 59: 1227-1236 (2003).

3. M. M. Jadhao, L.J. Paliwal, N.S. Bhave, Desalination, 2474: 56-465 (2009).

4. B.L. Rivas, I Moreno-Villoslada, J. Appl. Polym. Sci., 69: 817-824 (1998).

5. B.L. Rivas, E. D. Pereira, I. Moreno-Villoslada, Prog. Polym. Sci., 28 173-208 (2003)

6. B.L. Rivas, E.D. Pereira, M. Palencia, J. Sánchez, Progr. Polym. Sci., 36: 294-322 (2011).

7. B.L. Rivas, E. Pereira. H.A. Maturana, Angew. Makromol. Chem., 220: 61-74 (1994)

8. B.L. Rivas, E.D. Pereira, Bol. Soc. Chil. Quím., 45: 165-171 (2000).

9. I. Moreno-Villoslada, B.L. Rivas, L. N. Schiappacasse, E. Pereira, Polymer, 45: 1771-1775 (2004).

10. Ullman's Encyclopedia of Industrial Chemistry, 5th Ed.; VCH, 1986.

11. K. Kim, J.W. Cho, Korean J. Chem. Eng.,14: 162 - 167 (1997).

12. A.M. Sastre, F.J. Alguacil, Chem. Eng. J., 81: 109-112 (2001).

13. X. Liansheng, Z. Qixiu, G. Bofan, H. Shaoying, Int. J. Refract. Metals Hard Mater., 19: 145-148 (2001).

14. J.M. Juneja, S. Singh, D.K. Bose, Hydrometallurgy, 41: 201- 209 (1996).

15. E. Guibal, C. Milot, J. Roussy, Sep. Sci. Technol., 35: 1021-1038 (2000).

16. T. Hu R.J. HaynesY.-F. Zhou A. Boullemant, I. Chandrawana, Water Research, 71: 32-41 (2015).

17. K. Wejman-Gibas, , K. Wieszczycka, A. Wojciechowska, K. Ochromowicz, P. Pohl., Sep. Sci. Technol., 158:71-79 (2016).

18. P.C.H Mitchell, in Ullmann's Encyclopedia of Industrial Chemistry, 5th Ed., 1990, A16, Chap. 7, pp 675-682 and references therein. 19. J. Aveston, E.W. Anacker, J.S Johnson, Inorg. Chem., 3:735-742 (1964). 20. R.H. Busey, O.L. Keller, J. Chem. Phys., 4: 215-221(1964).

21. Morales D.V., Rivas B. L., and Escalona N., Polym. Bull., 73(3), 875-890 (2016).

22. Zeng, L. \& Yong Cheng, C, Hydrometallurgy, 98:10-20 (2009).

\section{ACKNOWLEDGEMENTS}

The authors thank to FONDECYT (Grant No 1150510). 